\title{
Syntactic Prediction Adaptation Accounts for Language Processing and Language Learning
}

This is a preprint version of a manuscript accepted for publication at Language Learning, please cite as:

Havron, N., Babineau, M., Fiévet, A-C., de Carvalho, A., \& Christophe, A. (in press) Syntactic prediction adaptation accounts for language processing and language learning. Language Learning.

Naomi Havron, ${ }^{\mathrm{a}, \mathrm{b}}$ Mireille Babineau, ${ }^{\mathrm{a}, \mathrm{c}}$ Anne-Caroline Fiévet, ${ }^{\mathrm{a}}$ Alex de Carvalho, ${ }^{\mathrm{a}, \mathrm{d}}$ and Anne Christophe $^{\mathrm{a}}$

${ }^{\text {a }}$ Laboratoire des Sciences Cognitives et Psycholinguistiques (LSCP), Département d'études cognitives (DEC), École normale supérieure (ENS), Université Paris Sciences et Lettres (PSL); École des hautes études en sciences sociales (EHESS), ${ }^{b}$ University of Haifa, ${ }^{\mathrm{c}}$ Department of Psychology, University of Toronto, ${ }^{\mathrm{d}}$ Laboratoire de Psychologie du Développement et de l'Éducation de l'Enfant (LaPsyDÉ), La Sorbonne, Université de Paris

This work was supported by the French National Research Agency (grant numbers ANR-17EURE-0017, ANR-11-0001-02 PSL*, ANR-12-DSSA-0005-01, and ANR-17-CE28-0007-01). We would like to thank Vireack Ul and Michel Dutat for technical support and Leticia SchiavonKolberg for help in testing. We would also like to thank the children who participated in this study and their parents.

Correspondence concerning this article should be addressed to: Naomi Havron, 199 Aba Khoushy Ave., Haifa, Israel. email: nhavron@psy.haifa.ac.il.

The handling editor for this article was Theres Grüter. 
Previous studies have shown that children use recent input to adapt their syntactic predictions and use these adapted predictions to infer the meaning of novel words. In the current study, we investigated whether children could use this mechanism to disambiguate words whose interpretation as a noun or a verb is ambiguous. We tested 2- to 4-year-old French children using the phrase la petite followed by a homophone that could be interpreted as either a noun or a verb. We assigned the children to a noun condition or a verb condition. Before the test, those in the noun condition were exposed to sentences where la petite predicted nouns, and those in the verb condition to sentences where la petite predicted verbs. At testing, 3- to 4-year-olds, but not 2year-olds, from the verb condition looked at the verb interpretation longer than did the children in the noun condition. This suggests a progression in children's ability to rely on input to adapt their predictions in language comprehension.

Keywords syntactic priming; language acquisition; prediction; child language; language processing; homophones; syntactic adaptation; ambiguity resolution 


\section{Introduction}

According to error-based learning models, to comprehend language, children are constantly predicting what their interlocutors will say next, and, when their predictions fail, they correct the model on which they rely for prediction to better fit upcoming input. Language learning is accomplished through this Bayesian optimization process that serves to build a linguistic representation of children's native language(s). The suggestion that language learning happens through amending prediction, that is, linguistic representations, thus also predicts that the adaptation process will operate in the same way in language processing and language learning (Chang, Dell, \& Bock, 2006; Chang, Kidd, \& Rowland, 2013; Rabagliati, Gambi, \& Pickering, 2016). In effect, according to these models, the traditional distinction between processing and learning is undermined. As children listen to sentences, they process these sentences to both comprehend them and change the model on which they rely for processing and learning novel linguistic material. When children process sentences, minor to no changes will be made to their linguistic representations if a sentence is fully predictable. However, unexpected or previously unencountered words or constructions result in changes to their representations, which can be described as language learning. Thus, according to these models, whether a subsequent sentence contains a word that children know or a novel word, children use the exact same processes. However, in this study, we adopted the more traditional distinction between processing and learning in order to examine the hypothesis that these error-based prediction processes operate in the same way in learning and processing. In this study, we have described inferring the meaning of novel words as learning and processing familiar words and structures as language processing.

\section{Background Literature}


Error-based learning models also predict that children, whose linguistic representations are less robust because they have had less experience with language, should be more prone to change their predictions in the face of prediction error, relative to adults (and younger children should be more prone to do so than older children, Peter, Chang, Pine, Blything, \& Rowland, 2015). Although there has been interest in error-based models or in adaptation to linguistic context (henceforth, prediction adaptation), direct evidence for these two key (and closely related) hypotheses remains scarce. First, there is little research directly comparing language processing and language learning. Second, although some evidence exists for developmental changes in prediction, only a few studies have compared prediction adaptation across age groups (Fazekas, Jessop, Pine, \& Rowland, 2020; Havron et al., 2020).

Indirect evidence for prediction adaptation in children has come from studies showing that children can be structurally primed to produce a structure to which they have recently been exposed, for example, the passive voice (Gámez \& Vasilyeva, 2015; Peter et al., 2015). The current central theory explaining structural priming effects states that children show priming effects as a by-product of error-driven learning. As they successfully process incoming input, they change the model on which they rely for prediction to incorporate the primed structures (Branigan \& Messenger, 2016; Chang et al., 2006; Kholodova, Peter, Rowland, \& Allen, 2019; Peter et al., 2015). Thus, evidence of priming has been taken to be evidence for adaptation. Some of these studies tested predictions stemming directly from the error-driven account of priming, such as long-term effects of priming and stronger priming for more surprising primes, and found results that supported predictive adaptation (e.g., Branigan \& Messenger, 2016; Fazekas, Jessop, Pine, \& Rowland, 2020; Peter et al., 2015). However, all these studies explored language production without evaluating the impact of priming on either comprehension or language 
learning. Because production-comprehension asymmetries are abundant in child language, with comprehension abilities being generally faster developing than production skills (e.g., Fraser, Bellugi, \& Brown, 1963, though see also Grimm, Müller, Hamann, \& Ruigendijk, 2011, in which some studies show the reverse pattern), one should not assume that priming effects from production can be directly translated to priming in comprehension. In adults, syntactic priming in production has generally been found to be larger and more abstract than in comprehension; in many comprehension priming studies, priming effects have been found only when the same lexical verb is repeated in the prime and the target sentence. These differences have been explained by appealing to methodological differences, including which structures tended to be used for priming when production or comprehension was tested because, when the methodology was kept constant between comprehension and production (e.g., and fMRI study using passive sentences in both production and comprehension), priming effects have looked similar (Segaert, Kempen, Petersson, Hagoort, 2013; Segaert, Menenti, Weber, Petersson, Hagoort, 2012; Tooley \& Bock, 2014). Moreover, priming comprehension allows researchers to examine structures and cognitive effects that they would not be able to test in production (e.g., global ambiguity resolution).

Although there have been multiple comprehension studies with adults (see Tooley \& Traxler, 2010, for a review), studies on comprehension priming in young children have been sparse. One study by Thothathiri and Snedeker (2008), showed that 3- to 4-year-old children can be primed to expect either a double-object construction (e.g., give the cat the milk) or a prepositional-object construction (e.g., give the milk to the cat). In target sentences, after hearing give the... children looked predictively at the recipient (cat) if they had been primed with double-object constructions and at the theme (milk) if they had been primed with prepositional- 
object constructions. However, this study focused on anticipation of an ending of an incomplete sentence and not on interpretation of completed sentences—globally ambiguous sentences where both interpretations remain possible until the end. If priming is the result of changing a model to better comprehend language, then one would expect recent experience to also impact children's interpretation of ambiguous sentences. That is, children should not only anticipate but also rely on their expectations in order to understand interlocutors when the interlocutors' intention can be understood in different ways (ambiguous sentences). Recently, one study found such effects in 5to 6-year-old children (Havron et al., 2020). However, although both Thothathiri and Snedeker (2008) and Havron et al. (2020) looked at language processing, these studies did not ask whether language learning had occurred through prediction adaptation.

A more direct piece of evidence that children are learning through prediction adaptation comes from two recent studies. Fazekas et al. (2020) primed 5- to 6-year-old children's and adults' language production using more or less surprising sentences. Surprising prime sentences were those in which verbs appeared in less expected syntactic structures. For example, the verb give is more frequently used with a double object construction (e.g., give the dog a bone) than with a direct object construction (e.g., give the bone to the dog). The participants who had been primed with more surprising sentences showed larger change in their production of the primed construction in a postpriming testing phase. The participants in this experiment changed their production of familiar syntactic structures; an effect which suggests that surprising input (i.e., failed predictions) incites changes to underlying syntactic representations. In this Fazekas et al. (2020) study, the primed construction and all target words were familiar to the participants, and thus, learning was only revealed in the use of each sentence structure relative to each other. 
Another recent study tested the effect of prediction adaptation on children's learning of novel words. Havron, de Carvalho, Fiévet, and Christophe (2019) found that 3- to 4-year old children can rely on their experience with familiar sentences to change their prediction of encountering either a noun or a verb after an ambiguous syntactic context. These children later relied on these predictions to infer the meaning of novel words. In French, the words la petite can be followed by either nouns or verbs, such that petite could act as an adjective describing a noun (e.g., la petite grenouille "the little frog"), or act as a noun, short for la petite fille "the little girl" (e.g., la petite dort "the little one is sleeping"). During an induction phase, 3- to 4-year-old French-speaking children were presented with familiar nouns or verbs following the syntactic context la petite, as in the examples above. During testing, the children were presented with a novel word that could be interpreted as either a noun or a verb (e.g., la petite nuve "the little nuve" or "the little one is nuving"). The participants who had been exposed to four sentences where the word following la petite was a familiar verb were more likely to interpret a novel word appearing in the same syntactic context as denoting a novel action than were the participants who had been presented with sentences where the word following la petite was a familiar noun. This was the first demonstration that children can indeed rapidly change their predictions and use these updated predictions for language learning.

\section{The Present Study}

The current study focused on two central predictions of the error-driven-learning model mentioned above. The first was that, as children process sentences, they build a predictive model that they will use in the same way both when they are acquiring novel words and when they are processing familiar words. Thus, the very same effects that are shown in learning should be evident in processing. We used the design of Havron et al.s' (2019) experiment to test children's 
processing of familiar sentences. Unlike Havron et al., we did not present novel words during the test but presented ambiguous sentences containing noun/verb homophones. For example, the sentence la petite ferme can be interpreted either as "the little farm" or "the little one is closing." French-learning infants as young as 20 months old have been previously shown to understand both the verb and noun meanings of these homophones and to be able to use prosodic information to disambiguate the two possible interpretations (de Carvalho, Dautriche, \& Christophe, 2016; de Carvalho, Dautriche, Lin, \& Christophe, 2017). The current experiment used prosody that was ambiguous between a noun and a verb interpretation as in Havron et al. (2019). If children rely on recent experience with linguistic input to infer the meaning of a word presented after the syntactic frame la petite, they should look longer at (i.e., indicate a preference for) an image depicting the verb interpretation of a homophone (e.g., in the case of ferme, a little girl closing a chest) when they have previously been presented with familiar verbs than when they have previously been presented with familiar nouns.

We tested adaptation of expectations in language comprehension and compared the effect that we found in the current study with the effect found in Havron et al. (2019). Finding a similar effect would suggest that, as children successfully process sentences, they change the model on which they rely for both processing and learning novel linguistic material. We predicted that, whether the test sentence contained a word that the participants knew (processing) or that they did not yet know (learning), they would rely on their adapted expectations to predict the syntactic category of that word.

A second prediction of the error-driven-learning model was that children whose prior knowledge is less robust should be more prone to change their predictions in the face of prediction error (as was found by Peter et al., 2015). We tested this prediction by looking at two 
different age groups: 24- to 30-month-old toddlers and 3- to 4-year-old children. We expected that the younger age group would show stronger adaptation than would the older age group. However, as stated above, 24- to 30-month-olds might be less able to rapidly integrate novel linguistic input than are 3- to 4-year-olds due to the limited cognitive resources of younger children (e.g., memory, executive functions, language processing, see Diamond, 2013). If such cognitive resources variable(s) were predominant, we might in fact see a weaker effect in the younger group than in the older group, or even none at all. Despite a potential confound between the proposed underlying cognitive mechanism (prediction adaptation) and the cognitive resources allowing children to integrate linguistic input, we still hoped to contribute to this research agenda by presenting two age groups with the same adaptation task that should be simple and easy enough for 24- to 30-month-old toddlers to perform.

\section{Method}

All materials (Havron, Babineau, Fiévet, de Carvalho, \& Christophe, 2021a), data (Havron, Babineau, Fiévet, de Carvalho, \& Christophe, 2021b), and analysis scripts (Havron, Babineau, Fiévet, de Carvalho, \& Christophe, 2021c) have been made publicly available via IRIS (https://www.iris-database.org) and the Open Science Framework (https://osf.io/qnt93/?view_only=cf930630a087406fa16961b65182009a).

The experimental design and planned analysis were preregistered with the Open Science Framework and can be accessed with the same Open Science Framework link as above.

\section{Participants}

Children were recruited and tested in our baby laboratory through direct contact with parents belonging to our database. We had two age groups: 24- to 30-month-olds (henceforth 2-yearolds) and 3- to 4-year-olds. Our final sample for the 2-year-old group consisted of 48 
monolingual French-speaking toddlers between the ages of 24.26 and 29.92 months (verb condition: $n=22,11$ girls, $M_{\text {age }}=26.25$ months, $S D=1.61$; noun condition: $n=26,12$ girls, $M_{\text {age }}=26.58$ months, $\left.S D=1.50\right)$. Our final sample for the 3- to 4-year-old group consisted of 49 monolingual French-speaking children between the ages of 36.39 and 49.84 months (verb condition: $n=24,12$ girls, $M_{\text {age }}=42.45$ months, $S D=4.35$; noun condition: $n=25$, 16 girls, $M_{\text {age }}=42.73$ months, $\left.S D=4.17\right)$. This sample size was similar in size to Havron et al.'s (2019) study, which found a Cohen's $d$ effect size of 0.94 (95\%CI [1.57,0.307]) with 45 participants.

Seven 2-year-olds of the 62 originally tested were removed due to fussiness (e.g., repeated attempts to leave the room). Five 3- to 4-year-olds of the 57 originally tested had corrupted data files. Trials were excluded if more than $50 \%$ of the eye-tracking data was missing for that trial, which led to 57 excluded trials for the 2-year-old participants ( 26 in the noun condition and 31 in the verb condition) and 42 excluded trials for 3- to 4-year-old participants (22 in the noun condition and 20 in the verb condition). Participants were excluded from the final analysis if they had more than two test trials with more than $50 \%$ missing eye-tracking data; seven 2-year-olds and three 3- to 4-year-olds were excluded for this reason. Of the 3- to 4-yearolds, 12 performed the experiment after having performed a different experiment that had lasted about 5 minutes and that had not included homophones or the frame la petite, none of whom had to be excluded. Written parental consent was obtained for all the participants. The study was approved by the local ethics committee, the Conseil d'évaluation éthique pour les recherches en santé (CERES IRB).

\section{Design}

In French, la petite can either be followed by a noun (e.g., la petite grenouille "the little frog") or by a verb (e.g., la petite dort "the little one is sleeping"). A search in a child-directed-speech 
corpus from Paris, France (Morgenstern \& Sekali, 2009) found that this lexico-syntactic frame is more likely to be followed by a noun (720 instances) than by a verb (six instances). We manipulated the syntactic category that this context predicted by randomly assigning the participants to one of two conditions: a verb condition or a noun condition. In the induction phase, the participants assigned to the verb condition were exposed to four sentences in which $l a$ petite was consistently followed by familiar verbs; whereas the participants assigned to the noun condition were exposed to four sentences in which la petite was consistently followed by familiar nouns. The participants additionally heard an equal number of filler sentences not using the phrase la petite and directing the noun-condition participants to look at verbs (always using the frame elle VERB "she VERB") and the verb-condition participants to look at nouns (always using the frame c'est une NOUN "it's a NOUN"). In the test phase, all the participants were exposed to four globally ambiguous sentences in which a noun-verb homophone could be interpreted either as a noun or as a verb (e.g., la petite ferme). We examined whether 3- to 4year-olds and 2-year-olds could use their updated expectations (built during the induction phase) to guide their syntactic analysis and thus infer the intended meaning of familiar noun/verb homophones during testing. If this were indeed the case, during testing, the 3- to 4-year-olds and the 2-year-olds from the verb condition should have been more likely to interpret the homophones as verbs than those assigned to the noun condition.

\section{Materials and Procedure}

The participants were tested individually in our baby laboratory in a sound-attenuated doublewalled booth. They sat facing a 27 -in. screen positioned $70 \mathrm{~cm}$ away from them. Eye gaze was recorded by an Eyelink-1000 (SR Research, 2010) placed below the screen (operating in remote mode and collecting data every $2 \mathrm{~ms}$ ). We used a 5-point calibration. The induction phase 
included eight trials: four induction trials and four fillers. On all trials, the participants saw two images displayed side by side on the screen: one depicting a little girl performing an action and the other showing an object. During the presentation of the two images, a woman's voice (the last author) asked the participants to look at one of the images in a child-friendly fashion. For instance, in an induction trial, for the pair of images involving an apple on one side and a girl sleeping on the other side, the participants assigned to the noun condition heard the sentence $O h$, regarde, la petite pomme! "Oh look, the little apple!” In contrast, the participants assigned to the verb condition would hear Oh, regarde, la petite dort! "Oh look, the little one is sleeping!" The verb image always included a little girl, and the noun image never did. The prosody was the same for noun and verb sentences. This was done by intentionally picking a prosody that was appropriate for both nouns and verbs and in which the three words belonged to the same prosodic phrase. Otherwise, it would have been possible for the participants to disambiguate the sentences using different prosodic structures (as shown by de Carvalho et al., 2016, 2017). Havron et al. (2019) pretested this prosodic contour with adults to make sure that both interpretations were possible. Adults judged the novel word to have referred to an action $31 \%$ of the time and to a novel object $69 \%$ of the time, confirming that the novel word could be interpreted as either a noun or a verb, yet showing a clear noun bias consistent with the child-directed-speech corpus search (see Havron et al., 2019, for details). See Figure 1 and Table 1 for prosodic characteristics of the different types of trials. 

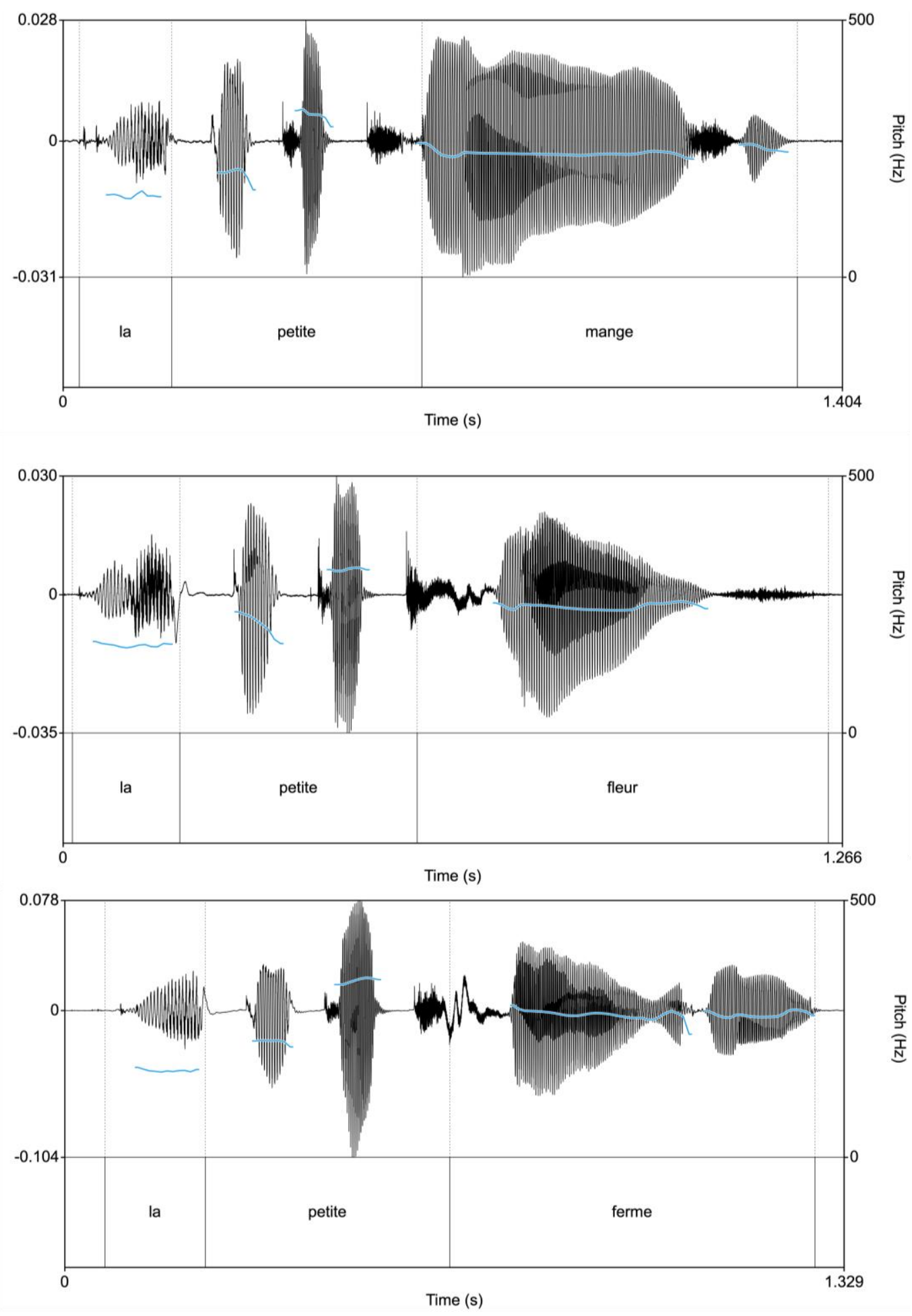

Figure 1 Soundwave and pitch for one verb phrase (la petite mange, top panel), one noun phrase (la petite fleur, middle panel), and one test phrase with a homophone (la petite ferme, bottom panel). 
Table 1: Summary of the acoustic measurements for the three types of experimental trials

\begin{tabular}{|c|c|c|c|c|c|c|c|c|c|}
\hline \multirow[b]{2}{*}{ Measurement } & \multicolumn{3}{|c|}{ Noun trials $(n=4)$} & \multicolumn{3}{|c|}{ Verb trials $(n=4)$} & \multicolumn{3}{|c|}{ Test trials $(n=4)$} \\
\hline & $M$ & $S D$ & $95 \% \mathrm{CI}$ & $M$ & $S D$ & $95 \% \mathrm{CI}$ & $M$ & $S D$ & $95 \% \mathrm{CI}$ \\
\hline $\begin{array}{l}\text { Duration rime } \\
\text { petite (in ms) }\end{array}$ & 154.41 & 22.59 & $\begin{array}{l}{[138.75,} \\
170.07]\end{array}$ & 169.34 & 35.28 & $\begin{array}{l}{[144.89,} \\
190.38]\end{array}$ & 169.48 & 30.7 & $\begin{array}{l}{[148.21,} \\
190.76]\end{array}$ \\
\hline $\begin{array}{l}\text { F0 rime petite (in } \\
\mathrm{Hz})\end{array}$ & 347.64 & 24.99 & $\begin{array}{l}{[330.32,} \\
364.95]\end{array}$ & 361.71 & 34.47 & $\begin{array}{l}{[337.82,} \\
385.59]\end{array}$ & 383.83 & 20.54 & $\begin{array}{l}{[369.6,} \\
398.06]\end{array}$ \\
\hline $\begin{array}{l}\mathrm{F} 0 e \text { in petite (in } \\
\mathrm{Hz} \text { ) }\end{array}$ & 238.07 & 19.69 & $\begin{array}{l}{[224.42,} \\
251.71]\end{array}$ & 243.62 & 27.72 & $\begin{array}{l}{[224.41,} \\
262.82]\end{array}$ & 257.43 & 18.51 & $\begin{array}{l}{[244.6,} \\
270.27]\end{array}$ \\
\hline
\end{tabular}

The four filler items used an unambiguous syntactic structure: c'est une + NOUN “it's a NOUN" for the verb condition or Elle + VERB "she is VERBing" for the noun condition, and directed the participants to look at the opposite syntactic category to the category they were being exposed to following la petite in their condition. That is, if participants were in the verb condition, they heard four la petite + familiar VERB sentences (e.g., la petite dort "the little one is sleeping") and four C'est une + familiar NOUN sentences (e.g., C'est une vache "this is a cow"). The filler trials assured that the participants were asked equally often to look at the action image or the object image in both conditions. The order of the trials was randomized, with the only constraint being that a given syntactic category should not appear more than twice in a row.

In the test phase consisting of four trials, the participants saw two images depicting the noun and verb interpretations of four homophones (e.g., for la petite ferme, they saw a little farm, and a little girl closing a chest). The ambiguous words were ferme [fєьт] "closes/farm," marche [тавJ] "walks/stair," porte [роьt] "carries/door," and sourit/souris [suьi] “smiles/mouse." In French there is no difference in pronunciation between souris and sourit; 
both words are pronounced as /subi/ because the final $s$ and final $t$ are silent. All these ambiguous words are known to children of young ages; 20-month-old infants have previously been shown to interpret similar ambiguous sentences as containing either a noun or a verb, depending on prosodic cues (de Carvalho et al., 2016; de Carvalho et al., 2017). Moreover, de Carvalho et al. (2017) also asked the parents of their participants to fill out a short questionnaire indicating whether their children understood each of the meanings of the ambiguous words used in their task (the same words that we used in our current study). These results suggested that most toddlers are able to understand most of the ambiguous words used in our task.

In our task, the participating 3- to 4-year-old children and the 2-year-old toddlers in both conditions saw the same images and heard the exact same sentences. The prosody of the test sentences was the same as that of the induction sentences - ambiguous as to whether the final word was a noun or a verb, and the same audio files were used for both conditions. The order of the test trials was randomized (except for the last trial, which, due to a programming error, was always la petite sourit/souris "smiles/mouse"). In all trial types, the side that the target image appeared on was counterbalanced. Each trial lasted about 30 seconds, with the full experiment lasting about 6 minutes. There was one difference between the protocol for the 2-year-olds and 3- to 4-year-old groups. For the 3- to 4-year-old group only, to make the experiment shorter, we removed the prepresentation of the two images together. That is, for the 3- to 4-year-old group images were presented one by one without naming, then the two images together and the sentences twice. For the 2-year-olds images were presented one by one without naming, then together in silence for three seconds, and only then the two images together and the sentence twice. We also made the prepresentation of single images shorter for the 3- to 4-year-olds. For a full-length sample trial see Figure 2. 


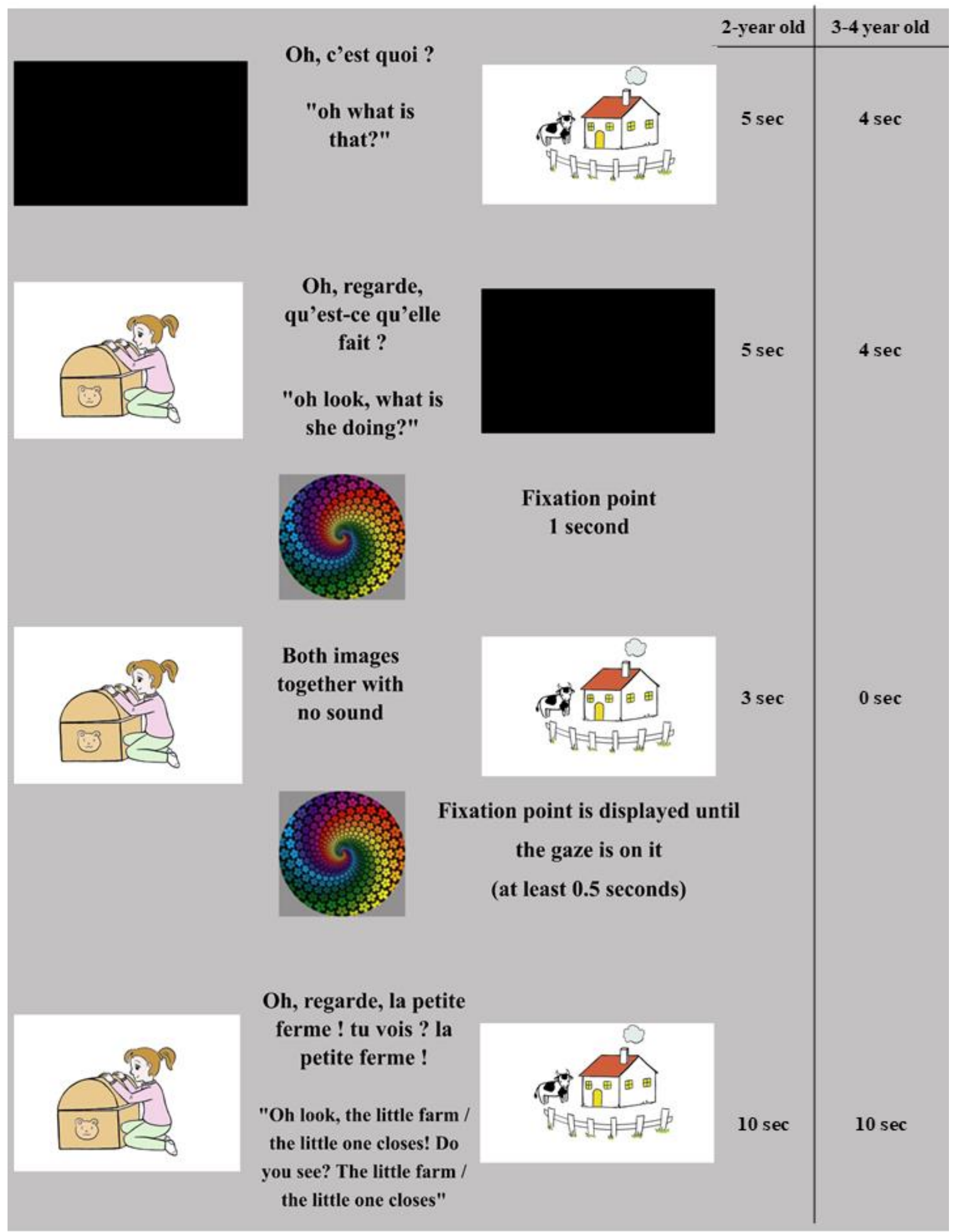


Figure 2 Example of the time-course of a test trial (side of the verb and noun interpretation was counterbalanced across trials). The online version of this article has color.

\section{Data analysis}

Current Experiment

For each participant in this experiment, we measured the time course of eye-gaze during each test trial. We ran two different analyses on the eye-gaze data in R (Version 3.6.3; R Core Team, 2020). First, we calculated the proportion of looks towards the verb image for each participant, averaged over the entire time window (the 10 seconds in which the two images appeared sideby-side and the sentence was playing twice), and conducted a mixed-effects regression using the lme4 package (Bates, Mächler, Bolker, \& Walker, 2015) to compare the overall looking time at the verb image averaged across the whole trial between the two conditions, the two age groups, and the interaction of condition and age. The analysis included a random intercept for participant and item. We calculated $p$ values using the lmerTest package (Kuznetsova, Brockhoff, \& Christensen, 2017). We obtained Bayes factors from the BayesFactor package (Morey, Rouder, Jamil, \& Morey, 2015) by calculating the ratio of the likelihood of each model to the likelihood of a model lacking the effect of interest. For example, for the effect of condition, we compared a model which included age and condition as fixed effects and participants and items as random effects to a model which included only age as a fixed effect and participants and items as random effects. We set our inference criterion for Bayes factor at $\mathrm{BF}_{10}>3$, which would indicate moderate evidence for $\mathrm{H} 1$.

Second, we ran two cluster-based permutation analyses (one for each age group) to find if there existed a specific time-window(s) where a significant effect of condition was observed. 
Adjacent time points (in 50ms bins) with a $t$ value greater than 1.5 were grouped together into a cluster, and the probability of observing a cluster of the same size (for the difference between the different conditions for each age group separately) by chance was estimated by running the same analysis on simulated data in which group was randomly assigned to participants $(1,000$ iterations). The same kind of analysis has been used in other eye-tracking studies using a similar preferential-looking paradigm with infants and preschoolers (e.g., de Carvalho, Babineau, Trueswell, Waxman, \& Christophe, 2019; de Carvalho et al., 2017; Von Holzen \& Mani, 2012; see also Maris \& Oostenveld, 2007, for a formal presentation of the analysis itself). For all frequentist analyses we used an $\alpha$ of 0.05 as our inference criterion.

\section{Comparison with Havron et al. (2019)}

To compare the effect of syntactic adaptation in this language-processing experiment with the effect of syntactic priming in language-learning, we directly compared our results with the results of Havron et al. (2019). We ran a linear model (in the 2019 dataset there was only one observation per participant so we did not use a mixed-effects model) and used Bayes factors derived from the BayesFactor package (Morey et al. 2015).

\section{Results}

\section{Current Experiment (Preregistered Analyses)}

Our first analysis, conducted on the average overall looking time per participant (excluding looks away, which were not significantly different between conditions), found no effect of condition: Collapsing across age groups, the participants from the verb condition were not more likely to look at the image illustrating the verb interpretation $(M=51 \%$ of the total looking time to both images excluding time spent looking away, $S D=23 \%$ ) than the participants from the noun 
condition $(\mathrm{M}=42 \%, \mathrm{SD}=21 \%), \mathrm{b}=0.03, \mathrm{SE}=0.02,95 \% \mathrm{CI}[0.02,0.07], t=1.26, p=.29, d=$ $0.53, \mathrm{BF}_{10}=0.17$. This effect suggested that the participants from the verb condition were more likely to interpret the homophone as a verb than were the participants from the noun condition, the Bayes Factor shows moderate evidence for H0. We also found no significant effect of age (collapsing across condition) $(b=0.003, S E=0.01,95 \%$ CI $[-0.02,0.03], d=0.01, t=0.25, p=$ $\left..8, \mathrm{BF}_{10}=0.79\right)$, the Bayes Factor shows anecdotal evidence for H1. Importantly, we found a significant interaction between the variables condition and age, $b=0.05, S E=0.01,95 \%$ CI $[0.3$, $0.8], t=4.25, p<.001, \mathrm{BF}_{10}=165.18$, such that only the 3 - to 4 -year-olds (verb: $M=57 \%, S D=$ 15\%; noun: $M=38 \%, S D=11 \%, d=1.45,95 \%$ CI $[2.10,0.81]$ ) but not the 2 -year-olds (verb: $M$ $=45 \%, S D=17 \%$; noun: $M=49 \%, S D=13 \%, d=-0.24,95 \%$ CI $[-0.82,0.35])$ showed an effect of condition. The Bayes Factors indicates extreme support for H1 (see Figure 3). It should be noted that the variance in the verb condition was larger than the variance in the noun condition.

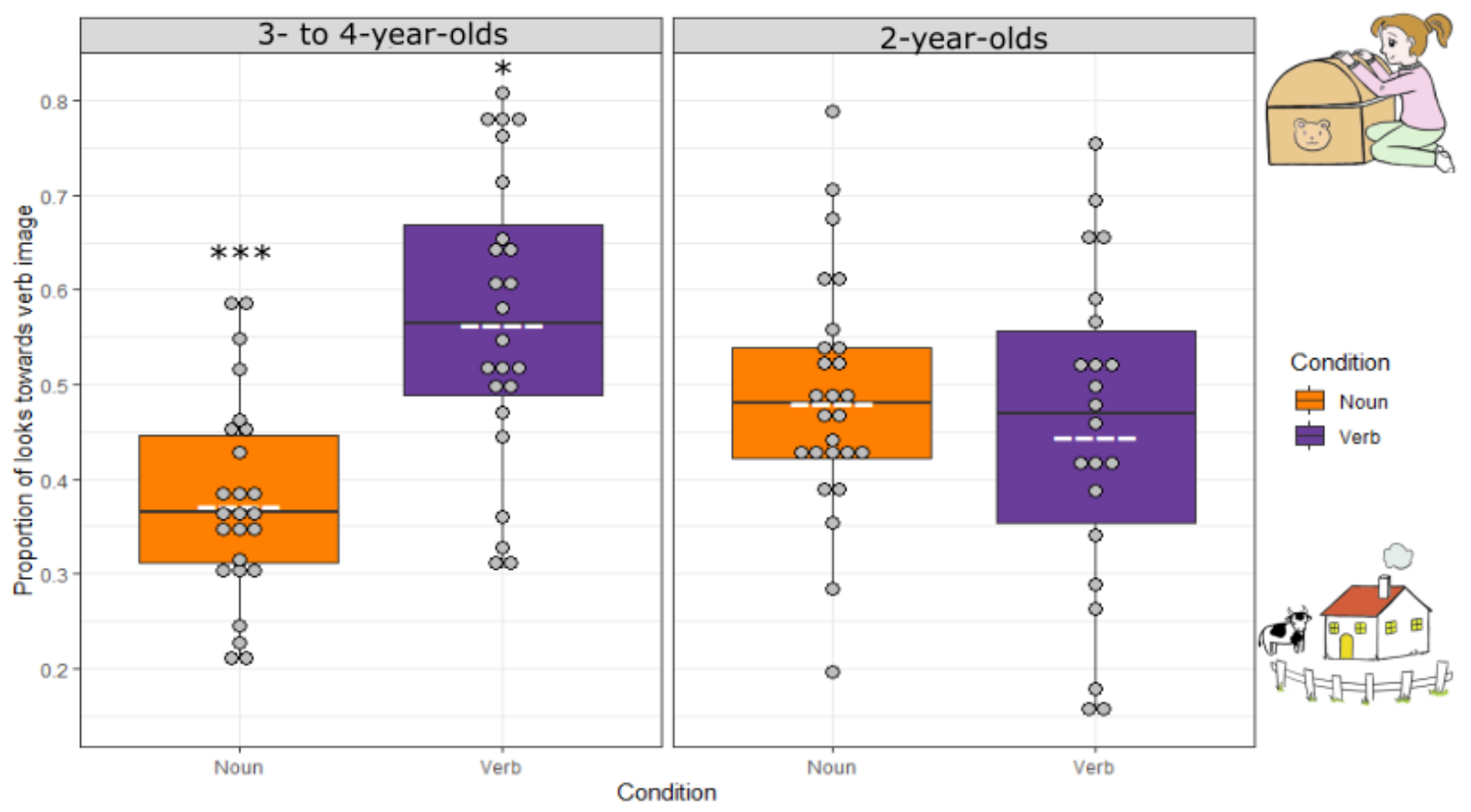


Figure 3 Mean overall proportion of looks toward the verb image during the test trials for the two conditions and two age groups. Gray dots represent values for each individual participant. The lower and upper hinges correspond to the first and third quartiles, the dotted white lines represent the means, and the black lines within the squares represent the median. The whiskers represent either 1.5 times the inter quartile range, or the minimum/maximum value if that value is closer to the mean than 1.5 times the inter quartile range. Purple marks the verb condition and orange marks the noun condition. The 3- to 4-year-olds from the verb condition looked at the verb image significantly more than did the 3- to 4-year-olds from the noun condition, but this difference was not the case for 2-year-olds. Asterisks mark the difference from chance level $\left(^{*} p\right.$ $<.05, * * * p<.001)$

For 3- to 4-year-olds, the cluster-based analysis revealed two significant time windows with an effect of condition. The first significant cluster $(p=.016)$ was found between 2,850 ms and 4,650 ms after the beginning of the trial, which was about $400 \mathrm{~ms}$ after the beginning of the target word that started on average at $2,474 \mathrm{~ms}$. The second significant cluster $(p<.001)$ was found between 5,500 $\mathrm{ms}$ and 9,500 ms after the beginning of the trial, which was before the start of the second repetition of the target word that started on average at 6,729 ms (see Figure 4). During these time-windows, the 3- to 4-year-olds from the verb condition looked more at the verb interpretation than did the 3- to 4-year-olds from the noun condition. For the 2-year-olds, no time cluster that was significantly different between the conditions was identified (see Figure 4). 


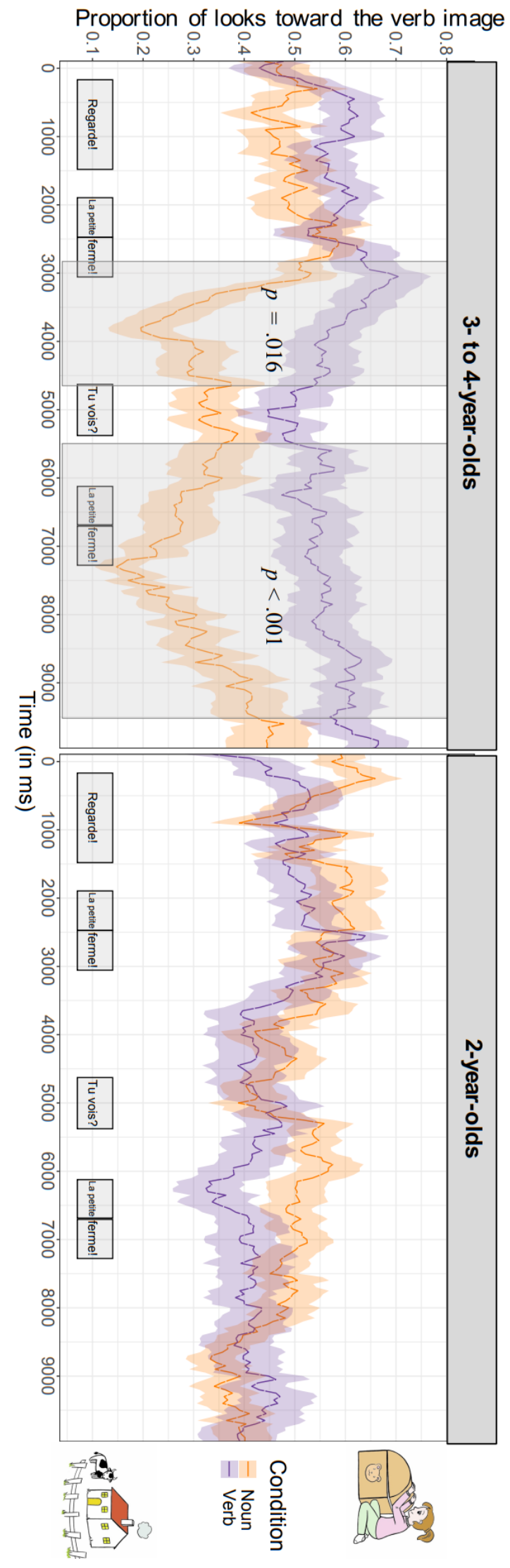


Figure 4 Proportion of looks toward the verb image in the test phase for the two conditions and two age groups as a function of time, plotted for the entire duration of the trial. Purple marks the verb condition and orange marks the noun condition. Significant time clusters are marked by a grey box. On the right are the two images for one test trial (ferme which means both "close" and "farm"), to exemplify that a higher proportion of looks to the verb images signifies more looks to images such as the girl closing the chest.

\section{Exploratory Analyses (Not Preregistered)}

\section{Induction Phase}

To examine whether the lack of effect in the 2-year-olds was due to the fact that they were not able to perform the task correctly or were inattentive during the induction phase, we ran the same mixed effects regression for looking time on the results of the induction phase. That is, we compared the overall looking time at the verb image, averaged across the whole trial, between the two conditions, the two age groups, and an interaction of condition and age. The analysis included a random intercept for participant and item. We found an effect of condition. Collapsing across age groups, the participants from the verb condition were more likely to look at the image illustrating the verb interpretation than were the participants from the noun condition, $b=0.19$, $S E=0.02,95 \% \mathrm{CI}[0.15,0.23], t=10.53, p<.001$. We also found a significant effect of age; the 2-year-olds looked at the noun interpretation longer than did the 3- to 4-year-olds, $b=-0.04, S E$ $=0.02,95 \% \mathrm{CI}[-0.08,-0.01], t=-2.12, p=.03$. Last, we found no interaction of age and condition, $b=0.004 S E=0.03,95 \%$ CI $[-0.05,-0.06], t=0.14, p=.89$. There was thus no evidence that the two age groups differed in their performance during the induction phase.

\section{Comparison with Havron et al. (2019) (Preregistered Analyses)}


Last, we compared our results from the 3-to-4-year-olds with the results of Havron et al. (2019), whose participants were of the same age. We ran this analysis to test the hypothesis that language learning and language processing act in the same way because, as we explained in the Background Literature section, they are one and the same according to the error-driven learning model.

We ran a mixed effects model predicting overall looking time per participant as a function of condition, experiment, and interaction between condition and experiment. The analysis included a random intercept for participant and item. We found a significant effect of condition, $b=0.19, \mathrm{SE}=0.04,95 \% \mathrm{CI}[0.12,0.27], t=5.16, p<.001, \mathrm{BF}_{10}=159,918.1$, showing that the 3- to 4-year-olds were adapting to recent input over the two experiments, with the Bayesian Factor showing extreme evidence for H1. We also found a main effect of experiment, $b=0.10, S E=0.04,95 \% \mathrm{CI}[0.03,0.18], t=2.72, p=.008, \mathrm{BF}_{10} 10=3.23$, indicating that the 3- to 4-year-olds were overall looking more at the verb interpretation in Havron et al. (2019) than in the current experiment. We discuss this finding below. We found no significant interaction $\left(b=-0.07, S E=0.05,95 \% \mathrm{CI}[-0.18,0.04], t=-1.34, p=.18, \mathrm{BF}_{10}=\right.$ 0.56, see Figure 5), with the Bayes Factor showing anecdotal evidence for H1, leaving as an open question whether the effect of condition was similar in size to Havron et al. (2019), with novel words, or even stronger with familiar words (the current experiment). 


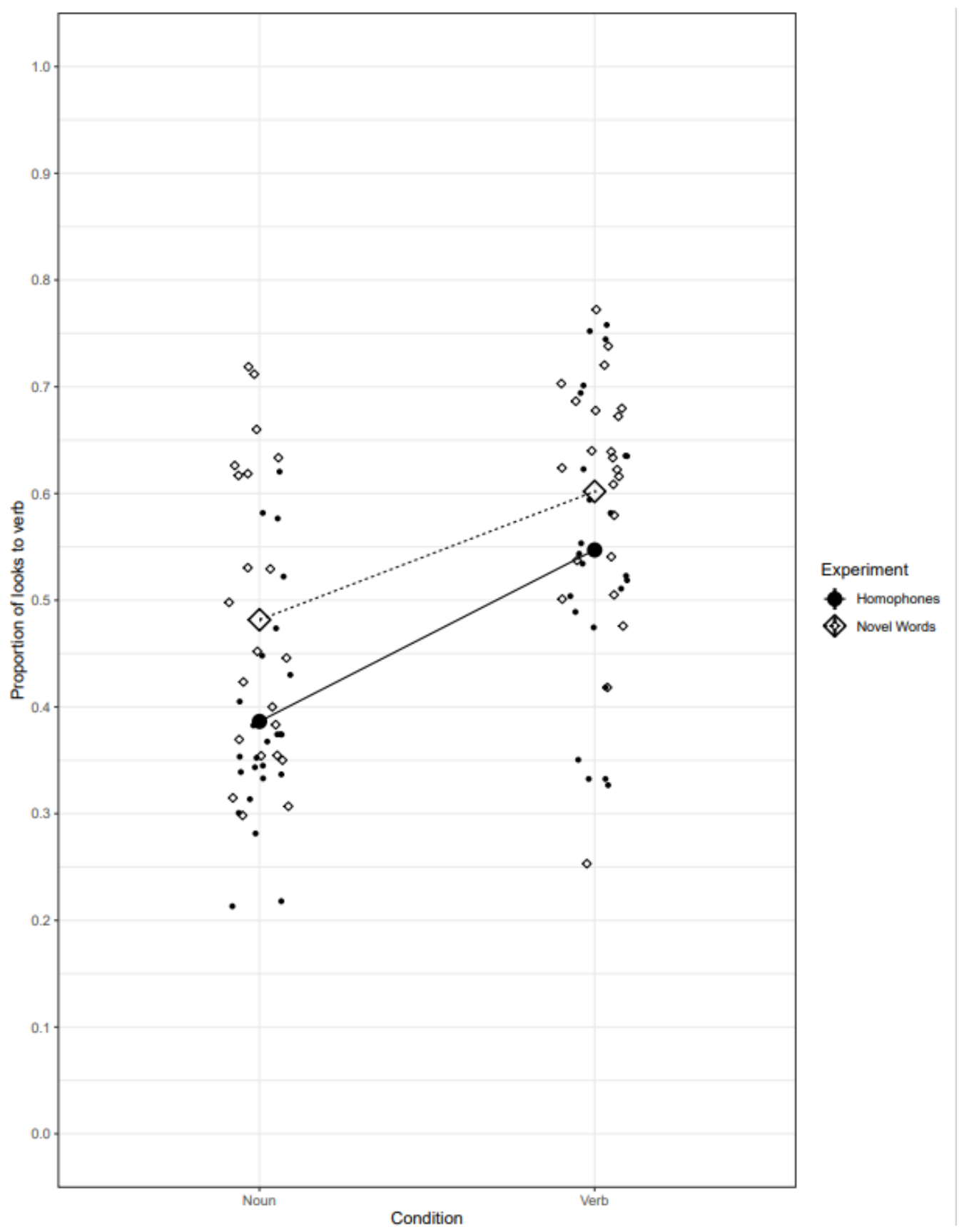

Figure 5 Proportion of looks toward the verb image/video in the test phase for the two conditions for the two experiments. The novel-words experiment (Havron et al., 2019) is marked with empty diamonds and a dashed line; the current experiment using homophones is marked with full circles and a full line. Each circle or diamond is a participant, and the big circles and diamonds mark the mean for that condition. 
Regarding the main effect of experiment, the 3- to 4-year-olds in Havron et al. (2019) had a slight bias towards the verb interpretation, but the 3- to 4-year-olds in the current experiment had a slight bias towards the noun interpretation. The verb bias in Havron et al. (2019) can be explained by the fact that the experiment used videos to illustrate the meaning of novel actions, and, because there was more motion in the action videos than in the object videos, it seems plausible that the participants tended to look more at the videos with more motion. One possible reason for the noun bias in the current experiment, which used familiar words depicted by still images, might be the linguistic biases in French-la petite is indeed much more likely to be followed by a noun than by a verb in French.

\section{Discussion}

The current study examined the effect of syntactic adaptation to recent linguistic experience on 3- to 4-year-olds' and 2-year-olds' interpretation of ambiguous sentences containing homophones. It has recently been shown that young children can use their experience with current linguistic input to update their syntactic expectations and that they are able to use their updated expectations to infer the meaning of novel words (Havron et al., 2019). In this study, we extended these findings by asking first, whether the effects found for language learning would hold for language processing (interpretation of ambiguous sentences with familiar words), and, second, whether this is also true for toddlers who are at an earlier stage in their language acquisition. We found that the 3- to 4-year-olds indeed showed adaptation of their expectations for a noun or a verb following a syntactic context (la petite), as exhibited by a higher likelihood of interpreting a homophone as a verb for children in the verb condition than for those in the 
noun condition. However, the 2-year-olds did not show an effect of recent linguistic experience on their interpretation of ambiguous sentences.

After finding that the 3-to-4-year-olds were indeed adapting their expectation in language processing, our next step was to compare the magnitude effect of syntactic adaptation in our child group with the effect found in Havron et al. (2019) in a language learning task. We found that the effects were of similar magnitude, or even slightly larger in the current experiment. Thus, whether the participants were tested on their processing of well-known words or on their ability to infer and learn the meaning of novel words, they exhibited the same behavior, adjusting their expectations based on their recent linguistic experience. Overall, manipulating the likelihood of encountering a noun or a verb after la petite affected both inference about novel word meaning and the interpretation of familiar homophones. Only one previous study has shown that 3- to 4-year-old children can be syntactically primed in language comprehension (Thothathiri \& Snedeker, 2008; see Havron et al., 2020, for similar results with 5- to 6-year-old children), and our results therefore add an important finding to the literature on syntactic priming in young children. These findings suggest that young children can be primed not only to expect a different ending to an unambiguous sentence as in Thothathiri and Snedeker's study (2008) but also that they can be primed to interpret a fully ambiguous sentence in a certain way.

The fact that the 3- to 4-year-olds from the noun condition showed a preference for the noun interpretation but that the 3- to 4-year-olds from the verb condition seemed to waver between the two possibilities, showing larger variance, should also be discussed. Given the higher frequency of the noun interpretation in children's input, one would expect children to show some amount of noun preference even without an induction phase. This preference would only be strengthened by an induction phase. The 3- to 4-year-olds from the verb condition, 
however, had some experience with a verb interpretation but expected it to be rare. These participants did not seem to simply reverse a lifelong bias towards a noun interpretation but rather to be less certain and more conflicted about their interpretation, wavering between both images. This pattern is the reverse of that found by Havron et al. (2019), which showed a verb preference in the verb condition, but children in the noun condition showed greater variance. Havron et al. hypothesized that the verb preference stemmed from the greater amount of motion in the action video compared to the object video, attracting even noun-condition children's gaze toward the verb interpretation, and that if this artifact could be removed, a noun bias would emerge. Our current findings support this hypothesis. More direct support could be obtained in future studies by including a pretest baseline and then measuring the change during testing. In such a context, one would expect all children to show a preference for the noun interpretation at the pretest, but, after the induction phase, the change in looks to the verb interpretation would reflect how their predictions have changed.

A second important finding of the current study is that the 2-year-olds failed to show the effect that was observed with the 3- to 4-year-olds. This finding does not support the prediction put forward by error-driven-learning account that younger children, whose prior knowledge is less robust than that of older children, will be more likely to change the model on which they rely for prediction in the face of prediction error. However, several confounds prevent us from drawing strong conclusions against this hypothesis.

According to error-driven-learning models, children cannot change their predictions without registering an error signal in the face of failed predictions. This is because prediction adaptation can only happen in response to prediction error. Because error signals depend on performance variables (which draw on cognitive resources that develop with age), the same 
stimulus may not cause the same error signal in the different age groups, making it nearly impossible to experimentally examine whether younger children are more prone to change their predictions than are 3- to 4-year-olds in the face of the same prediction error (Havron, Babineau, \& Christophe, 2021). That is, there is a possibility that our 2-year-olds were not comprehending or remembering the induction phase to the same degree (or with the same speed) as were the 3to 4-year-olds but that, if 2-year-olds' level of integration during the induction phase could be equated with that of 3- to 4-year-olds, they would show a larger change than that of 3-to 4-yearolds. This challenge is compounded by the fact that task demands might bear more heavily on toddlers compared to young children and on children compared to adults, making it hard to find tasks that are equally challenging and engaging across all ages (e.g., Beretti, Havron, \& Christophe, 2020; Havron, et al., 2019, who found larger effects in adults than in children). One study by Peter et al. (2015) managed to create such comparable conditions, and observed larger adaptation in children than adults. In that study, the researchers manipulated the verb bias of the prime sentences to create more or less surprising primes, and thus larger or smaller error signals. They found a larger difference between surprising and unsurprising primes in children than in adults, in line with the expectation for larger prediction adaptation effects in children. However, a recent preregistered study with a similar design did not find a larger effect in children than in adults (Fazekas et al., 2020). Our study did not create such comparable conditions as these two studies. It is thus a limitation of the current study that we cannot disentangle the following three variables: developmental changes in children's underlying tendency to change their predictions, their lower abilities to process the linguistic context, and task demands.

The finding of an increase in effect with age is thus compatible with two possibilities: (a) The hypothesis put forward by error-driven-learning models is wrong; (b) 2-year-olds are less 
likely than are 3- to 4-year-olds to be able to process the induction phase successfully due to their lower ability to remember the stimuli, comprehend them, compute regularities in the input, or some combination of those. These two options both have the same real-world consequencesprediction adaptation improves with age (and/or with increased linguistic proficiency) as was found with predictions based on stable linguistic data (e.g., that an always precedes a vowel, Gambi, Gorrie, Pickering, \& Rabagliati, 2018). However, it is theoretically important to disentangle these two options. In our exploratory analysis, we found equal success in the induction phase for the two age groups, implying that both the 3- to 4-year-olds and the 2-yearolds understood the induction sentences and were as attentive to them. This finding does not mean that the toddlers were as likely to remember the items, integrate them, or abstract from them, but it does offer some support for the first option, that the hypothesis proposed by the error-driven learning model is incorrect.

Additional support that infants have no problem integrating the information during induction phase successfully comes from a recent study with 28-month-old toddlers who were able to make use of an induction phase to infer the meaning of a novel word (de Carvalho, Dautriche, Fiévet, \& Christophe, 2021; see also Yuan \& Fisher, 2009). In the test phase of that study, toddlers were presented with a novel word in an ambiguous context (e.g., he will dase). When an induction phase dialogue contained this novel verb integrated within right-dislocated and intransitive sentences (He will dase, the dad'! Really? He will dase?), toddlers interpreted the verb as intransitive in the test phase. However, toddlers who watched a dialog containing this verb either in transitive contexts or right-dislocated contexts only, interpreted the novel verb as transitive. Although these results support the idea that toddlers are able to remember and integrate an induction phase, they again do not mean that the infants were as likely to abstract 
from the induction phase and deploy their predictions when encountering words that were absent from the induction phase (as was needed in the current study). In addition, these findings are not directly comparable to ours because the toddlers in our experiment were required to adapt their life-long syntactic bias of expecting a noun following the context la petite, but the toddlers in de Carvalho et al.'s (2021) experiment were only required to activate their representation of rightdislocated sentences.

If error-driven accounts of language learning are wrong in hypothesizing that younger children, whose representations of linguistic knowledge are less robust than older children, show larger changes in their representation in response to error-signals, an alternative explanation to account for these results is needed. One such possible explanation is that, like other cognitive capacities resources (e.g., memory, executive functions, language processing; see Diamond, 2013), the ability to predict improves with age. This could be the case if, for example, prediction relies on other such resources or if the improvement in functional connectivity or availability of neural resources leads to improved ability to predict (see Huettig, 2015).

\section{Conclusion}

To conclude, we found that our 3- to 4-year-olds showed adaptation of their expectations for a (familiar) noun or verb following the ambiguous syntactic context la petite; the likelihood of interpreting a homophone following la petite as a verb was higher for the 3- to 4-year-olds in the verb condition compared to the likelihood for the 3- to 4-year-olds in the noun condition. This result is comparable to a previous study which found that 3- to 4-year-olds showed adaptation of their expectations for a noun or a verb following the syntactic context la petite when inferring the meaning of novel words. Thus, the two studies combined suggest that whether the next sentence contains an ambiguous word that they know (processing) or a novel word (learning), children 
rely on their adapted expectations to predict the category to which the word following la petite belongs.

The 2-year-olds did not show the same effect as the 3- to 4-year-olds. Thus, our results do not directly support the hypothesis, put forward by error-driven models, that younger children adapt more than older children in response to an error signal. However, there are alternative explanations that could account for the differences of effect for the 2-year-olds in our task: their yet limited development of the cognitive skills that would be necessary for integrating the induction phase, task demands, or difficulty in overriding overall biases (i.e., expecting a noun after la petite). Further studies should find suitable ways to disentangle these possibilities.

\section{References}

Bates, D., Mächler, M., Bolker, B., \& Walker, S. (2015). Fitting linear mixed-effects models using lme4. Journal of Statistical Software, 67,1-48. https://doi.org/10. 18637/jss.v067.i01

Beretti, M., Havron, N., \& Christophe, A. (2020). Four-and 5-year-old children adapt to the reliability of conflicting sources of information to learn novel words. Journal of Experimental Child Psychology, 200, 104927. https://doi.org/10.1016/j.jecp.2020.104927

Branigan, H. P., \& Messenger, K. (2016). Consistent and cumulative effects of syntactic experience in children's sentence production: Evidence for error-based implicit learning. Cognition, 157, 250-256. https://doi.org/10.1016/j.cognition.2016.09.004

Chang, F., Dell, G. S., \& Bock, K. (2006). Becoming syntactic. Psychological Review, 113(2), 234-272. https://doi.org/10.1037/0033-295X.113.2.234

Chang, F., Kidd, E., \& Rowland, C. F. (2013). Prediction in processing is a by-product of language learning [Commentary on Pickering \& Garrod: An integrated theory of language 
production and comprehension]. Behavioral and Brain Sciences, 36, 350-351. doi:10.1017/S0140525X12001495.

de Carvalho, A., Babineau, M., Trueswell, J. C., Waxman, S. R., \& Christophe, A. (2019).

Studying the real-time interpretation of novel noun and verb meanings in young children. Frontiers in Psychology, 10, 1-16. https://doi.org/10.3389/fpsyg.2019.00274

de Carvalho, A., Dautriche, I., \& Christophe, A. (2016). Preschoolers use phrasal prosody online to constrain syntactic analysis. Developmental Science, 19, 235-250.

https://doi.org/10.1111/desc. 12300

de Carvalho, A., Dautriche, I., Fiévet, A. C., \& Christophe, A. (2021). Toddlers exploit referential and syntactic cues to flexibly adapt their interpretation of novel verb meanings. Journal of Experimental Child Psychology, 203, 105017. https://doi.org/10.1016/j.jecp.2020.105017

de Carvalho, A., Dautriche, I., Lin, I., \& Christophe, A. (2017). Phrasal prosody constrains syntactic analysis in toddlers. Cognition, 163, 67-79. https://doi.org/10.1016/j.cognition.2017.02.018

Diamond, A. (2013). Executive Functions. Annual Review of Psychology, 64(1), 135-168. https://doi.org/10.1146/annurev- psych-113011-143750

Fazekas, J., Jessop, A., Pine, J., \& Rowland, C. (2020). Do children learn from their prediction mistakes? A registered report evaluating error-based theories of language acquisition. Royal Society Open Science, 7(11), 180877. https://doi.org/10.1098/rsos.180877

Fraser, C., Bellugi, U., \& Brown, R. (1963). Control of grammar in imitation, comprehension, and production. Journal of Verbal Learning and Verbal Behavior, 2, 121-135. https://doi.org/10.1016/S0022-5371(63)80076-6 
Gambi, C., Gorrie, F., Pickering, M. J., \& Rabagliati, H. (2018). The development of linguistic prediction: Predictions of sound and meaning in 2-to 5-year-olds. Journal of Experimental Child Psychology, 173, 351-370. https://doi.org/10.1016/j.jecp.2018.04.012

Grimm, A., Müller, A., Hamann, C., \& Ruigendijk, E. (Eds.). (2011). Productioncomprehension asymmetries in child language (Vol. 43). Berlin, Germany: Walter de Gruyter.

Gámez, P. B., \& Vasilyeva, M. (2015). Exploring interactions between semantic and syntactic processes: The role of animacy in syntactic priming. Journal of Experimental Child Psychology, 138, 15-30. https://doi.org/10.1016/j.jecp.2015.04.009

Havron, N., Babineau, M., \& Christophe, A. (2021). 18-month-olds fail to use recent experience to infer the syntactic category of novel words. Developmental Science, 24(2), e13030. https://doi.org/10.1111/desc. 13030

Havron, N., Babineau, M., Fiévet, A. C., de Carvalho, A., \& Christophe, A. (2021a). Instructions and stimuli. Materials from "Syntactic prediction adaptation accounts for language processing and language learning" [Collection: Instructions and stimuli]. IRIS Database, University of York, York, UK. https://doi.org/10.48316/wvna-5075

Havron, N., Babineau, M., Fiévet, A. C., de Carvalho, A., \& Christophe, A. (2021b). Datasets from "Syntactic prediction adaptation accounts for language processing and language learning" [Dataset]. IRIS Database, University of York, York, UK.

\section{https://doi.org/10.48316/3khf-t713}

Havron, N., Babineau, M., Fiévet, A. C., de Carvalho, A., \& Christophe, A. (2021c). $R$ code. Materials from "Syntactic prediction adaptation accounts for language processing and language learning" [Software/Analysis code]. IRIS Database, University of York, York, 


\section{UK. https://doi.org/10.48316/md47-xw78}

Havron, N., Carbajal, J.M., Scaff, C., Linzen, T., Barrault, A., \& Christophe, A. (2020). Priming syntactic ambiguity resolution in children and adults. Language Cognition and Neuroscience, 35, 1445-1455 https://doi.org/10.1080/23273798.2020.1797130

Havron, N., de Carvalho, A., Fiévet, A., \& Christophe, A. (2019). Three- to four-year-old children rapidly adapt their predictions and use them to learn novel word meanings. Child Delevopment, 90, 82-90. https://doi.org/10.1111/cdev.13113

Huettig, F. (2015). Four central questions about prediction in language processing. Brain Research, 1626, 118-135. https://doi.org/10.1016/j.brainres.2015.02.014

Kholodova, A., Peter, M., Rowland, C. F., \& Allen, S. (2019, November). Abstract representations in bilingual L2 speaking children over development in a structurally biased language. Poster presented at the 44th Annual Boston University Conference on Language Development (BUCLD 44), Boston, MA.

Kuznetsova, A., Brockhoff, P.B., \& Christensen, R.H.B. (2017). lmerTest package: Tests in linear mixed effects models. Journal of Statistical Software, 82(13), 1-26. http://doi.org/10.18637/jss.v082.i13

Maris, E., \& Oostenveld, R. (2007). Nonparametric statistical testing of EEG-and MEG-data. Journal of Neuroscience Methods, 164, 177-190. https://doi.org/10.1016/j.jneumeth.2007.03.024

Morey, R. D., Rouder, J. N., Jamil, T., \& Morey, M. R. D. (2015). Package 'BayesFactor' [Computer software]. https://cran.r-project.org/web/packages/BayesFactor/BayesFactor.pdf Morgenstern, A., \& Sekali, M. (2009). What can child language tell us about prepositions? A contrastive corpus-based study of cognitive and social-pragmatic factors. In J. Slatev, M. Andrén, M. Johansson Falk, \& C. Lundmark, Studies in language and cognition (pp. 261-275). Newcastle upon Tyne, UK: 
Cambridge Scholars Publishing.

Peter, M., Chang, F., Pine, J. M., Blything, R., \& Rowland, C. F. (2015). When and how do children develop knowledge of verb argument structure? Evidence from verb bias effects in a structural priming task. Journal of Memory and Language, 81, 1-15. https://doi.org/10.1016/j.jml.2014.12.002

R Core Team. (2020). R: A language and environment for statistical computing (Version 3.6.3) [Computer software]. Vienna, Austria: R Foundation for Statistical Computing. http://www.R-project.org/

Rabagliati, H., Gambi, C., \& Pickering, M. J. (2016). Learning to predict or predicting to learn? Language Cognition and Neuroscience, 31, 94-105.

https://doi.org/10.1080/23273798.2015.1077979

Segaert, K., Kempen, G., Petersson, K. M., \& Hagoort, P. (2013). Syntactic priming and the lexical boost effect during sentence production and sentence comprehension: An fMRI study. Brain and Language, 124, 174-183. https://doi.org/10.1016/j.bandl.2012.12.003

Segaert, K., Menenti, L., Weber, K., Petersson, K. M., \& Hagoort, P. (2012). Shared syntax in language production and language comprehension-an fMRI study. Cerebral Cortex, 22, 1662-1670. https://doi.org/10.1093/cercor/bhr249

SR Research. (2010). EyeLink 1000 User's Manual, Version 1.5. 2.

Thothathiri, M., \& Snedeker, J. (2008). Syntactic priming during language comprehension in three- and four-year-old children. Journal of Memory and Language, 58, 188-213. https://doi.org/10.1016/j.jml.2007.06.012

Tooley, K. M., \& Bock, K. (2014). On the parity of structural persistence in language production and comprehension. Cognition, 132, 101-136. https://doi.org/10.1016/j.cognition.2014.04.002 
Tooley, K. M., \& Traxler, M. J. (2010). Syntactic priming effects in comprehension: A critical review. Language and Linguistics Compass, 4, 925-937. https://doi.org/10.1111/j.1749818X.2010.00249.X

Von Holzen, K., \& Mani, N. (2012). Language nonselective lexical access in bilingual toddlers. Journal of Experimental Child Psychology, 113, 569-586. https://doi.org/10.1016/j.jecp.2012.08.001

Yuan, S., \& Fisher, C. (2009). "Really? She blicked the baby?" Two-year olds learn combinatorial facts about verbs by listening. Psychological science, 20, 619-626. https://doi.org/10.1111/j.1467-9280.2009.02341. 
